\title{
Looking beyond the warp and weft: unpicking latent narratives in clothing.
}

Shelly Goldsmith

We are intimately familiar with the physicality and materiality of clothing.

Although we all have our 'best' clothes, clothes are generally seen as ordinary, not 'elevated' to artistic levels, but the significance of the everyday and the familiarity of an item such as a blouse holds a perfect opportunity for me to test complex ideas and the blouse and the dress have become vehicles in recent work to do this. These familiar objects offer a fluid entry point to discuss and stimulate contemplation around inherited memory; biological and metaphorical transference; our sense of self and the ability of cloth and clothes to hold and translate human experience.

My paper outlines the origins and methods of the piece 'Lodz Blouse Trilogy' and the context in which it is created.

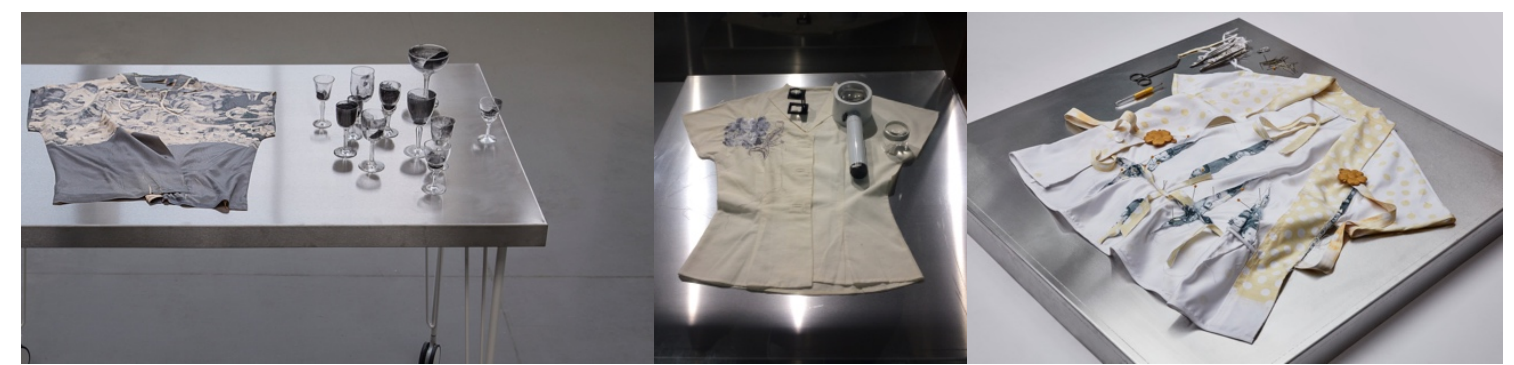

Three 'everyday' blouses are presented in the installation 'Lodz Blouse Trilogy'. The installation specifically addresses the use of textiles, cloth and clothing as a rich landscape for expression - a vehicle to explore and communicate complex ideas within a fine art context, fundamentally posing ideas and notions regarding cloth's ability to hold and translate human experience and memory. The work seeks to present knowledge and provoke thinking on a series of levels, from craft skills to contemporary scientific and psychological thinking.

The ideas behind this body of work were initiated over 20 years ago on a visit to the International Textile Triennial in Lodz, Poland. During the visit, I was moved by the rundown and broken nature of the of the city of Lodz; as if it had not healed since the barrages of WW2, the resonance of the experience was still palpable. Many years later I revisited these memories on discovering Chris Boot's book 'Lodz Ghetto Album', 2004 ${ }^{1}$ featured in an article in a Sunday supplement. Polish, Jewish, photographer Henryk Ross (1910 - 1991) was an official ghetto photographer working for the Department of Statistics. Whilst taking identification card photos he also recorded the daily life of the lives of the people living in the Lodz ghetto. His poignant and moving photos gave me an insight into the lives of the people who had lived in the city of Lodz during this difficult time. On further investigation, I learnt how Ross had buried his collection of photographs and gone into hiding, to later return and unearth them after the Red Army Liberation in 1945.

I never forgot Ross's work and for many years I was haunted by one photograph in particular. The image depicts a gathering of families and generations at a table set out for a meal. Most likely the occasion captured in the photo is the Seder Passover ceremony. 
The peering faces of the children, especially the young girls engaged me, as, with hindsight I fully appreciated what lay ahead for them.

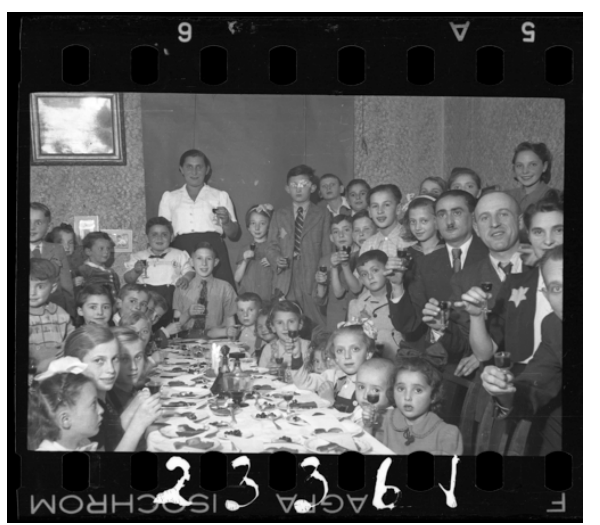

In 2014 the Art Gallery of Ontario ${ }^{2}$ (AGO) kindly gave me permission to explore the photographic image of this special family gathering in my work and so the material making of the piece 'Lodz Blouse Trilogy' began. The photograph, from AGO's dedicated collection The Lodz Ghetto Photographs of Henryk Ross: A Collection of Holocaust Photographs is titled 'Children and parents gathered around the table at a children's party, 1942-1944, a $3.4 \times 3.7 \mathrm{~cm}$ print from a $35 \mathrm{~mm}$ cellulose nitrate negative.

I undertook a series of interventions on 3 garments, 3 blouses (one reclaimed, two made using archival patterns) to hide and reveal latent matter. Using the imagery of the photograph 'Children and parents gathered around the table at a children's party, and inspired by Ross's acts to protect his original photographs and later unearth them, I explored ways I could mimic this process. The key element for me was that the Lodz family gathering was concealed within the construction/body or embellishment of everyday garments, with the ability to be worn without disclosing the evidence of the gathering and later through acts of deconstruction, unpicking and cutting these garments, the family gathering is revealed, unveiled and disclosed. The description 'latent' being critical to the work - latent, existing but not yet manifest, is dormant, hidden.

In between other projects, the blouses were made over a period of three years. Two of the blouses, 'Inherited' and 'Concealed' were individually exhibited as installations in exhibitions in the UK, France and Belgium³. The third blouse was resolved for the exhibition 'Lodz Blouse Trilogy' at the University for the Creative Arts, Canterbury, November 2016 to March 2017; the three pieces were staged in two large antique glass vitrines.

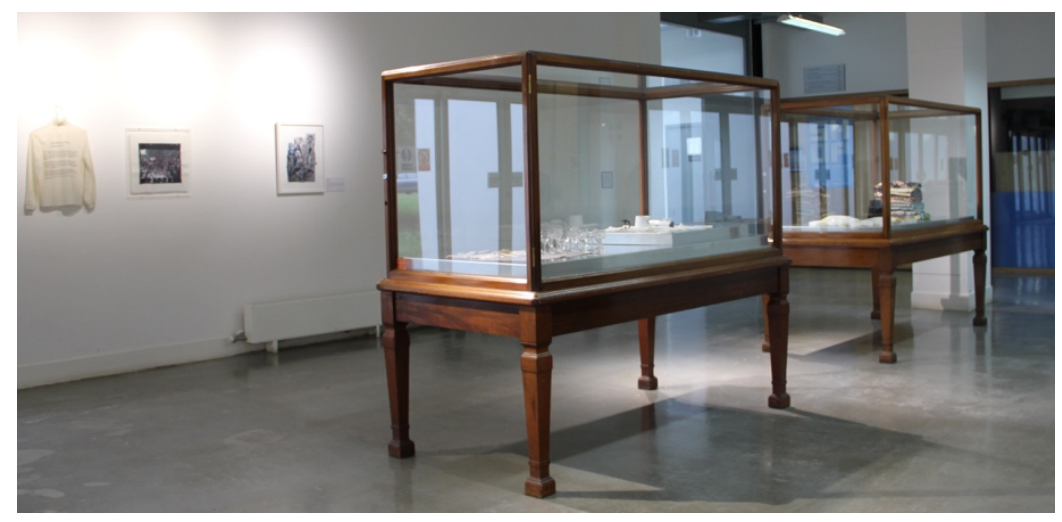

There is a challenge to exhibiting clothing without a fashion connotation taking over. Here, the use of the vitrines places the work clearly in the realm of the museum or gallery, clothing presented for looking at, for scrutiny and provocation. Strongly signaling the language of the gallery the vitrines tell the viewer that contrary to first impressions, these are no ordinary blouses. The two vitrines originate from the British Museum and came to me via the Beaney Museum, Canterbury. Protected in the raised glass boxes the three blouses are clearly no longer to be worn, or touched, but can be viewed with a 360 viewpoint, essential to fully appreciating the piece 'Concealed'. The weighty materials of the cases, the heavy carved wooden frame housing thick glass panels offers a solid 
structure to cradle these light, thin garments and brings an unyielding presence within the gallery space.

This body of work has its foundations in a fascination with the creative implications of what is left behind in the clothes we wear. In 2010 I worked with Alison Fendly, Senior biologist at the Forensic Science Service (FSS) to understand how she and her team extract and interpret latent matter in retrieved clothing. It was interesting to see how similar our methodologies were: her's scientific and mine artistic and how we both constructed a narrative from the garments we worked with. Alison's aim was to establish facts to support a police enquiry whereas mine was to explore and present ideas around the human condition; Alison Fendly described my outcomes as 'a different kind of truth'.

I have touched upon these ideas and reflected upon my experience at the FSS profusely within my practice. Guided by Edmund Locard's Exchange Principle, where he states 'every contact leaves a trace'. ${ }^{5}$ I have endeavored to make visible perceived memory and experience in everyday clothing. Originated by Locard in 1912, Locard's Exchange Principle is the basis for all forensic science and purports that wherever you go you leave a bit of yourself behind whilst taking away something from that environment. An act that is unseen, unfelt and often unnoticeable/undetectable.

Textiles play a powerful role in developing narrative in contemporary forensics. Kitty Hauser's paper 'A Garment in the Dock' ${ }^{6}$ describes the FBI's use of unique ridges and valleys in worn denim jeans to identify bank robbers This compelling research shows that despite the prevalence of jeans, each worn pair has individual identifying characteristics. Under forensic conditions and with analysis this can link the garment to the wearer. In Hauser's paper, she demonstrates how a retrieved garment from a suspect's home can be matched to CCTV footage. Hauser describes how "the unique wear of the jeans can be read like a barcode".

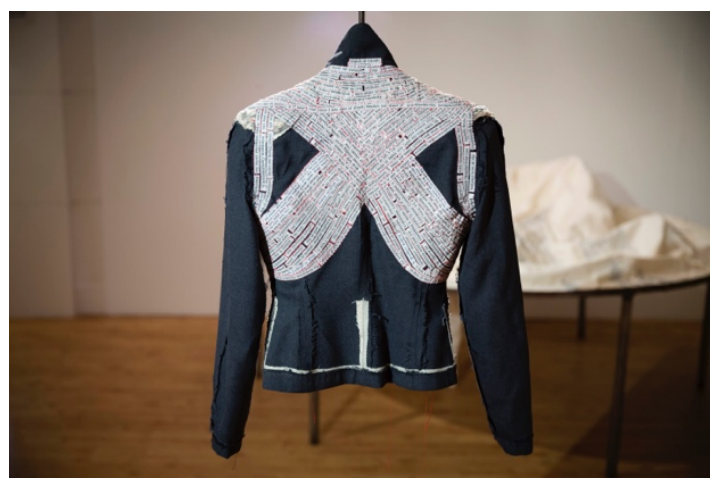

I work extensively with reclaimed garments in my practice, often picked up in charity shops or gifted to me. The circulation and wearing of my clothes, plus my mother's, my sister's and my daughter's have been fundamental in my work. For example, in my practice I have utilised garments my mother bought in 1951 with her first wage packet that I later wore in the 1980's. The piece 'Queen of Clouds', uses one of these garments together with copious

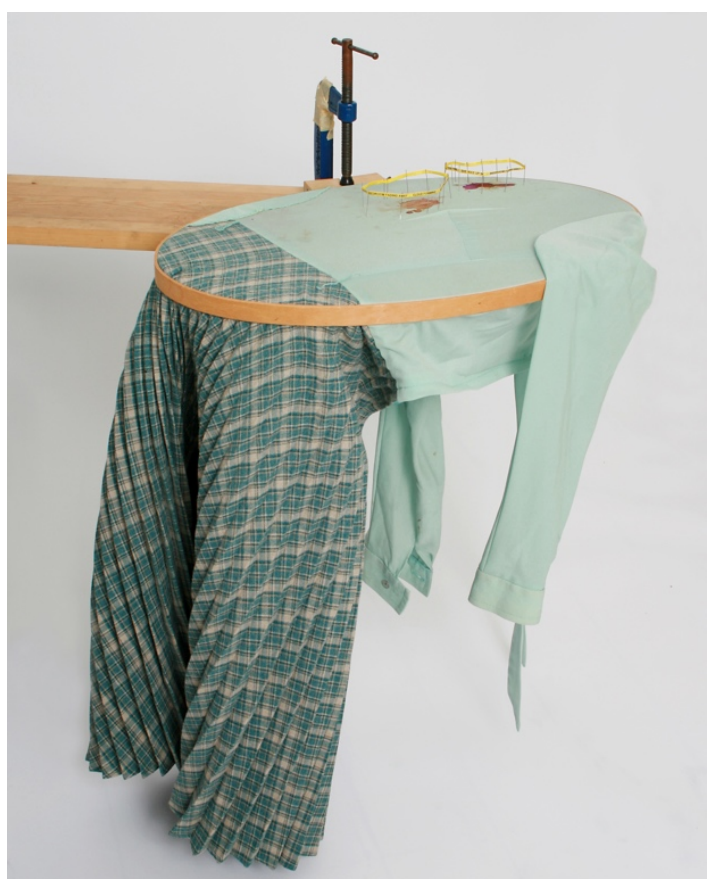
amounts of woven name tapes. Here, the sewn in tapes are not limited to the wearers initials or name, they become a biographical narrative which repetitively wraps and constrains.

The piece 'Scene 3\&4' installed at Pitzhanger Manor for the exhibition 'Revealing Evidence' ${ }^{7}$ , uses references to forensic science and its methods to artistically investigate stains on worn clothing, presenting a 'stain scene' as an imagined narrative. Drawing directly from my observations in the FSS laboratories the piece 'Scene 3\&4' re-imagines the procedure of 
processing stains on garments in their custody. A range of reactant chemicals are used to 'wash' even the smallest stains to identify its origin and content, hopefully revealing its DNA, all clues to the narrative of the garment, the experience of the wearer.

The exhibition 'Revealing Evidence' paired mother and daughter's garments side by side, in the pieces, 'English Landscape' \& 'Daughters Dress'. These pieces, in developing the use of staining, reference Rorschach ink blot tests, a psychological test routinely used in forensic situations; all the staining in the mother and daughter works are Rorschach-esq. As well as focusing on staining all three pieces, 'Scene 3\&4', 'English Landscape' \& 'Daughters Dress' mimic crime scene etiquette, where an area of significance is cordoned off and preserved for scrutiny. Here, the cordon tape is not a warning to 'keep out', as in routine police crime scenes, but reads as snippets of the perceived story of the stain site which it is protecting; ergo extracts from the narrative of the garment manifests the experience of its wearer.

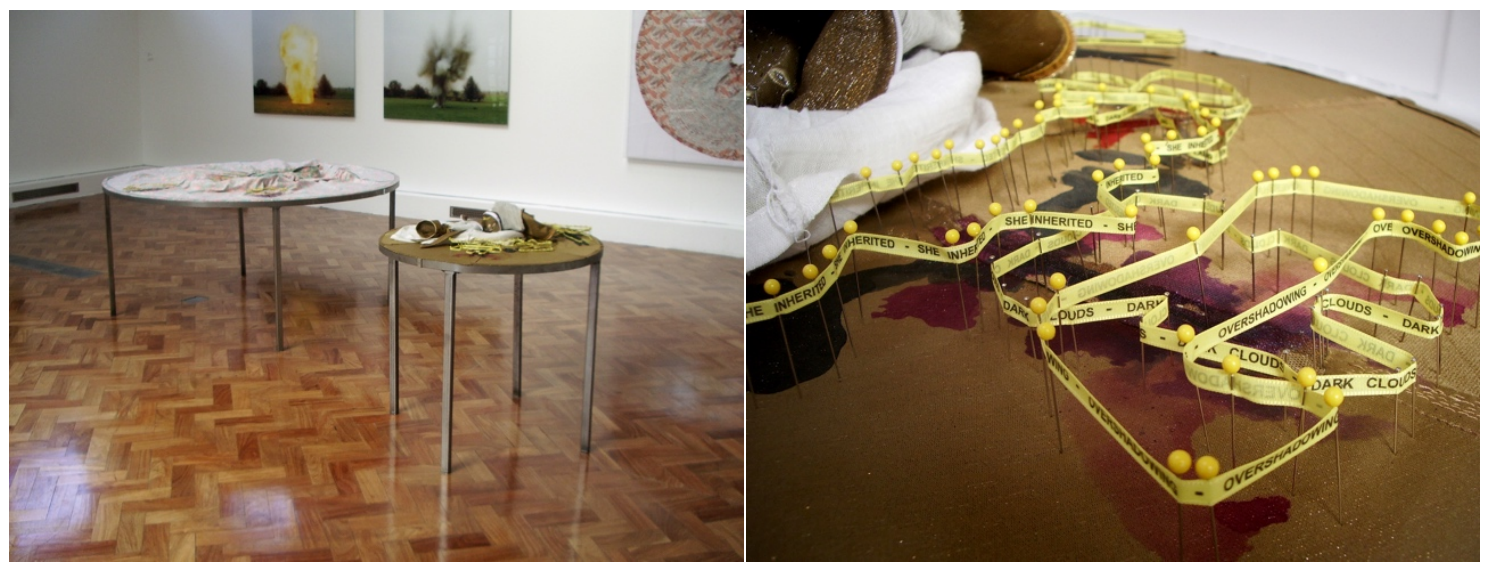

In 'English Landscape' the mother's narrative has a single layer cordon tape whereas in 'Daughters Dress' it is multilayered, the mother's narrative additionally filtered and developed through the offspring. Both these pieces aim to explicate narrative in worn clothing and illuminate the notion that maybe experience can be passed between generations and aim to ask questions about genetic, cultural and social inheritance.

My mother's experience of significant trauma, before I was born has always been a dominant presence in my own life and indeed my work. Prof Marcus Pembrey, in his piece 'Memories pass between generations' ${ }^{8}$, talks about the emergence of scientific findings to suggest there may be a permeation of experience passed between mother and child. He goes on to state that "the findings were highly relevant to phobias, anxiety and posttraumatic stress disorders" ${ }^{19}$ and provided "compelling evidence that a form of memory could be passed between generations" ${ }^{10}$. Known as trans-generational epigenetic inheritance, it seems that trauma in one generation can persist into the next. But to be clear, the references I am observing in my work do not suggest the passing down of specific memories, times and places but more an emotional response that has been inherited, not learnt.

Rachel Yehuda's study at New York's Mount Sinai Hospital of Jewish men and women who experienced or witnessed the inhumanity of Nazi camps says "there is some evidence to suggest that trauma from the Holocaust is passed epigenetically to their offspring"11. Yehuda analysed and compared genes from children who had experienced these atrocities with genes from Jewish children from families that did not reside in Europe during World War 2. "The gene changes in the children could only be attributed to Holocaust exposure in the parents", said Yehuda. Her work is the clearest example in humans of the transmission of trauma to a child via epigenetic inheritance ${ }^{\prime 12}$. The idea is controversial 
especially due to the small numbers of individuals in the study but it states "they found epigenetic tags on the same part of the gene in Holocaust survivors and their children; the correlation was not found in any of the control group and their children" ${ }^{13}$.

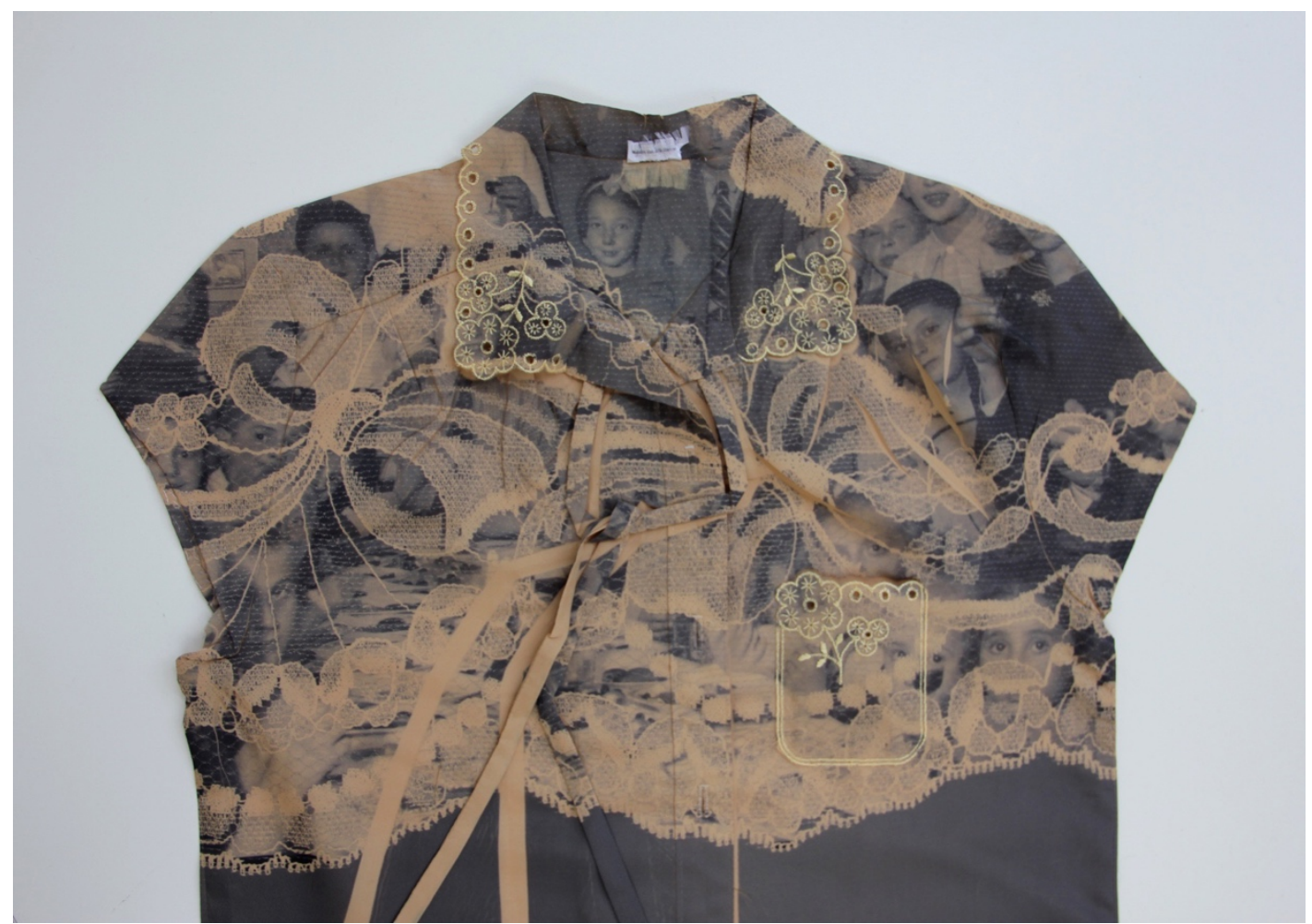

Each of the three blouses of 'Lodz Blouse Trilogy' has a distinct origin and technical approach. The first piece 'Inherited' was made initially for the 'Lace Effects 1 ' exhibition at Cité internationale de la dentelle et de la mode de Calais, France in response to their lace archive and the museum's site as a converted lace weaving factory, still with working lace looms. My own experience of lace has been as a cover up, to hide or disguise something unpleasant; a lace tablecloth thrown over an unsightly table, a lace collar applied to an old dress to pretty it up, lace nets at a window, a fine veil of lace concealment, which belies its respectable appearance.

Originally, as now, the looms at the Lace Museum are run using graphite to lubricate the parts. Now, some looms in the museum have been kept for demonstration purposes. But when the factory was in full production the graphite working the machines would have created copious amounts of graphite dust thrown up into the air and this was a key inspiration to this piece. Using dye sublimation technology, the piece 'Inherited' is an imagined scenario, a garment that has spent time in the loom environment, a layer of graphite dust settled on its surface. What is revealed when the large lace collar is removed? In 'Lodz Blouse Trilogy' installation 'Inherited' is paired with miniature drinking glasses, the same amount visible in Ross's photograph. However, unlike the photograph, in my manifestation, the glass vessels are now empty.

Looking at this historical photography we are aware of the plight of the individuals gathered around the table. Unlike the full glasses of the photograph, the glasses in my installation are symbolically empty vessels. 


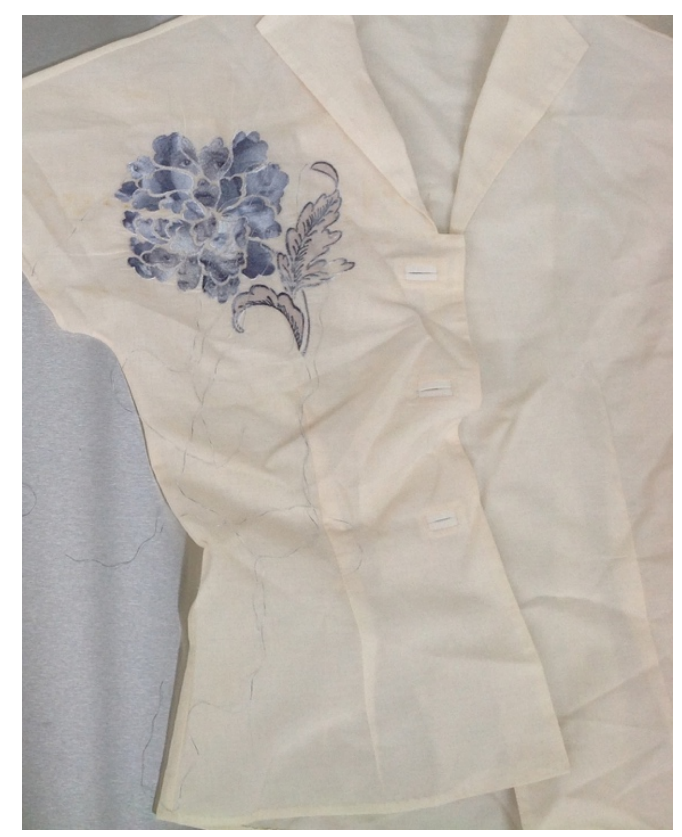

The second piece 'Concealed' is installed in 'Lodz Blouse Trilogy' with a series of high specification magnifying instruments akin to those used in the forensic/textile laboratory, a clue to the necessity for close observation in this piece. The blouse is a facsimile of an everyday wartime garment with a simple embroidered flower. 'Concealed' utilises digital embroidery and dye sublimation technology to conceal the imagery of the Lodz family gathering within the stitches of the flower. The plane of stitches creates a surface that distorts the imagery when not viewed straight on. The key to this piece is hiding in plain sight; the girl's faces reside in the flower all the time but are only experienced if the viewer is located in the right place to see them - view from the side and they are not visible.

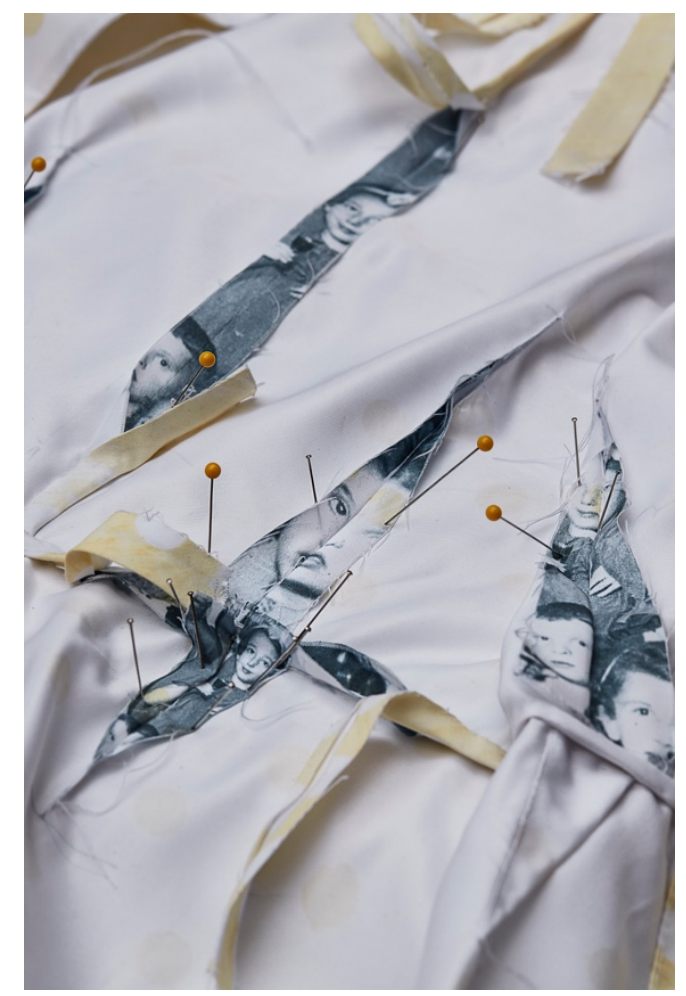

The third piece, 'Unpicked', is installed in the $2^{\text {nd }}$ glass cabinet, presented as a snapshot from a forensic lab or textile conservator's lab, there is a blouse in the process of being methodically deconstructed; all the necessary tools lined up beside it. The installation includes a stack of folded blouses ready for dissection. What is apparent on closer inspection of the partially unpicked blouse is that the image of the Lodz family gathering is hidden within the tightly bound seams and sewn darts of the blouse. Only now are they revealed as the garment is fragmented.

Was this a deliberate act of concealment? Has this used blouse, a hand-me-down, been carried around on the body of the wearer bearing the weight of this memory?

In conclusion, whether expressed scientifically or artistically, clothing has shown itself to be a rich conduit for exploring and presenting ideas pertinent to contemporary life, whilst also being a witness to our past. A new textiles landscape is detectable, provoking new scrutiny and cognizance of the clothes we wear, what of us is left behind in them and how can this be perceived, read and interpreted?

Fluent traditional and digital craft skills underpin the material manifestation of Lodz Blouse Trilogy whilst the comprehension of the cultural capital of cloth and clothing has made it possible to navigate and maximise the universal coding of clothing and garments in the piece. This paper acknowledges the personal origins in my work (somewhat previously negated, but maybe evident to the viewer). Now with a desire to embrace this even more, I am compelled to instigate opportunities to develop ideas that integrate textile and scientific process and thinking with a highly personal narrative. 
${ }^{1}$ Henryk Ross. Children and parents gathered around the table at a children's party, 1942-1944. 35 mm cellulose nitrate negative, Frame: 3.4 x 3.7 cm Gift from Archive of Modern Conflict, 2007. @2015 Art Gallery of Ontario 2007/2016.7

AGO. The Lodz Ghetto Photographs of Henryk Ross: A Collection of Holocaust Photographs http://agolodzghetto.com This website consists of over 4000 images from the Henryk Ross collection at the Art Gallery of Ontario.

${ }^{2}$ AGO. The Lodz Ghetto Photographs of Henryk Ross: A Collection of Holocaust Photographs Henryk Ross collection at the Art Gallery of Ontario.

Ross, Henryk.(1940-1944) The Lodz Ghetto Photographs of Henryk Ross: A Collection of Holocaust Photographs. [Photography] At: Ontario: Art Gallery of Ontario.

${ }^{3}$ 2016/17 'Haptic Tacit ' Leydon Gallery, London EC1 \& The Old Fire Station Gallery Oxford - with publication.

Goldsmith, Shelly. (2016) Inherited. [Textiles] At: Haptic Tacit. London: Leydon Gallery 25 - 29 October 2016

Goldsmith, Shelly. (2016) Inherited. [Textiles] At: Haptic Tacit. Oxford: The Old Fire Station Gallery 13 January - 4 March 2017.

2016 'A curated collection' Axis Contemporary Art Online. Curated by Sarah Martin, Turner Contemporary, Margate Goldsmith, Shelly. (2016) A Curated Collection. [Textiles] At: Margate: Turner Contemporary

2015 'Four Threads' Worshipful Company of Haberdashers, Spitalfields, London for OPEN LONDON

Goldsmith, Shelly. (2015) Settled [Textiles] At: Four Threads. London: The Worshipful Company of Haberdashers for Open London Festival 18 September - 19 September 2015.

2014 'Moving Textiles: Digital Encounters' University for the Creative Arts - curated by Jenna Rossi-

Goldsmith, Shelly. (2014) Learning to Sew, Concealed [Textiles] At: Moving Textiles: Digital Encounters. Canterbury: Hebert Read Gallery 20 June - 26 July 2014

2014 'Metamorphosis' TO3 Textile Incubation Centre, Ronse, Belgium.

Goldsmith, Shelly. (2014) Metamorphosis. [Textiles] At: Belguim: TIO3 Ronse 2014

2013 'Lace Effects 1' Cité internationale de la dentelle et de la mode de Calais, France Goldsmith, Shelly. (2013) Inherited [Textiles] At: Lace Effects 1. France: Lace and Fashion Museum Calais 6 October 2013 - 18 May 2014.

${ }^{4}$ Petherwick, WA. Turvey, BE. Ferguson, CE, 2012. Forensic Criminology. London; Elsevier Academic Press.

${ }^{5}$ 'A garment in the dock; or, how the FBI illuminated the prehistory of a pair of denim jeans' in Journal of Material Culture - November 1, 2004 - Kitty Hauser, Clare Hall, University of Cambridge, UK

Hauser, Kitty (2004) 'A garment in the dock; or, how the FBI illuminated the prehistory of a pair of denim jeans' In: Journal of Material Culture 9 (3) pp. 293-313.

${ }^{6}$ 'Revealing Evidence' Shelly Goldsmith \& Sarah Pickering - PM Gallery \& House, Pitzhanger Manor, London 15 Sept - 23 Oct 2010 Goldsmith,Shelly. Pickering, Sarah (2010) Revealing Evidence. [medium] At: London: Pitzhanger Manor Gallery \& House. 15 September 2010 - 23 October 2010.

7,8,9 'Memories' pass between generations' - James Gallagher, BBC News 1 Dec 2013 - quoting Prof Marcus Pembrey from University College London

Gallagher, James (2013) 'Memories' pass between generations'. In: BBC News [Online] At: http://www.bbc.co.uk/news/health25156510.

9,10,11 'Study of Holocaust survivors finds trauma passed on to children's genes' - Helen Thomson, The Guardian, 21 ${ }^{\text {st }}$ Aug 2015. Quoting Rachel Yehuda's report 'Holocaust Exposure Induced Intergenerational Effects on FKBP5 Methylation' in Biological Psychiatry: A Journal of Psychiatric Neuroscience and Theraputics - Rachel Yehuda, Nikolaos P Daskalakis, Linda M Bierer, Heather N. Bader, Torsten Klengel, Florian Holsboer, Elisabeth B. Binder

Thomson, Helen (2015) 'Study of Holocaust survivors finds trauma passed on to children's genes' In: The Guardian [online] At: https://www.theguardian.com/science/2015/aug/21/study-of-holocaust-survivors-finds-trauma-passed-on-to-childrens-genes Yehuda, Rachel (2016) “Holocaust Exposure Induced Intergenerational Effects on FKBP5 Methylation' In: Biological Psychiatry: A Journal of Psychiatric Neuroscience and Theraputics 80 (5) pp.372-380 